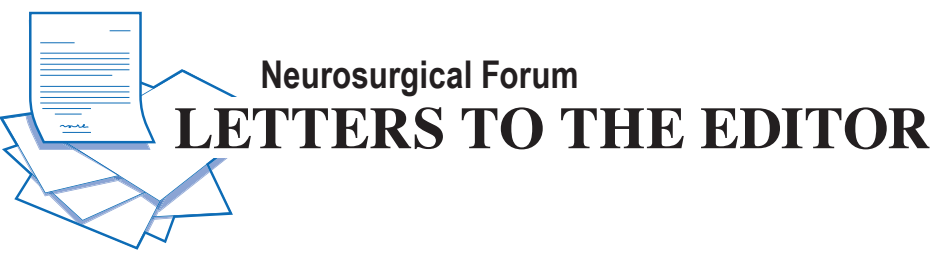

\section{Posterior transdural approach for cervical stenosis caused by retroflexion of anterior elements in a child with Pfeiffer syndrome}

TO THE EDITOR: We greatly enjoyed reading the article by Archer et al. ${ }^{1}$ (Archer J, Thatikunta M, Jea A. Posterior transdural approach for odontoidectomy in a child: case report. J Neurosurg Pediatr. 2020;25(1):8-12). We recently applied this same strategy in a child and would like to share our experience with this approach. Our patient was a 7-year-old girl with Pfeiffer syndrome who had undergone occiput-T1 posterior decompression and fusion 6 years earlier for occipitocervical instability and stenosis. She presented with progressive myelopathy, in- cluding neurogenic bowel and right-sided weakness. A CT scan showed that, although the patient had a stable posterior fusion with no loss of fixation, the anterior column had continued to grow. As a result, she developed extreme posterior retroflexion of the anterior elements of the spine, causing significant cord compression at the craniocervical junction (Fig. 1A). Based on preoperative imaging, it appeared as though the spinal cord was displaced to the left and that we would be able to access the retroflexed dens to the right posteriorly. However, we were unable to identify a safe operative corridor despite releasing the right $\mathrm{C} 2$ nerve root as it exited the foramen to widen the potential corridor, as the cord sat centrally draped over the dens; as such, the decision was made to perform the $\mathrm{C} 2$ and partial C3 corpectomies via a transdural approach (Fig. 1B). Following the decompression, the ventral dura was left open and the dorsal dura was closed using a Durepair patch

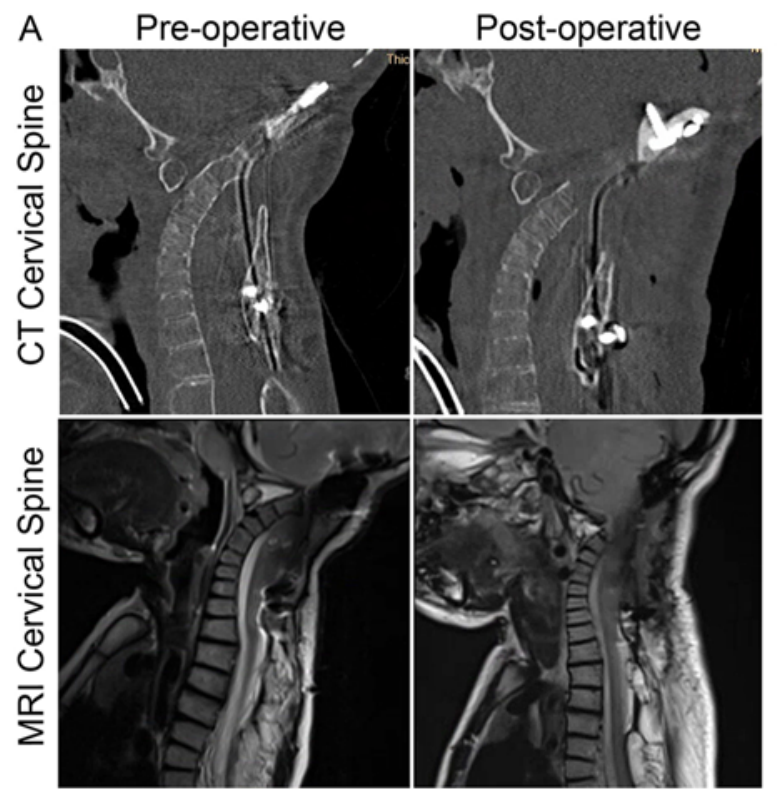

B Intra-operative

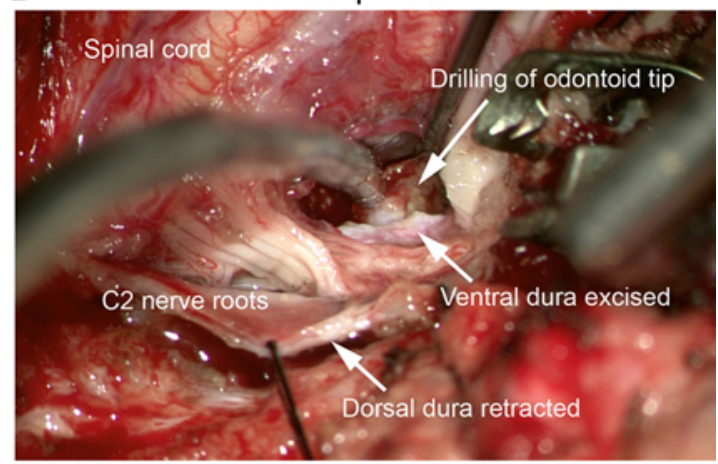

FIG. 1. Radiographic and intraoperative images showing decompression of the spinal cord from a posterior transdural approach. A: Preoperative sagittal CT and T2-weighted MR images (left) showing severe retroflexion of the anterior spinal column resulting in significant cord compression at the craniocervical junction. The anterior ring of $\mathrm{C} 1 \mathrm{can}$ be seen abutting the vertebral body of C3. There appears to be good bony fusion posteriorly, throughout the construct, with no signs of hardware failure. Postoperative sagittal CT and T2-weighted MR images (right) showing good decompression of the cervicomedullary junction. B: A transdural approach allowed for safe access to the odontoid, which was then drilled down using an eggshell technique. The spinal cord can be seen displaced to the left of the dens. Figure is available in color online only. 
(Medtronic) followed by DuraGen (Integra LifeSciences), TISSEEL (Baxter), and a blood patch. Postoperatively, she immediately regained bladder function but had transient worsened right-sided weakness, which improved with steroids and several days of medically elevated blood pressure. The patient is currently 1 month out from surgery.

Laura M. Prolo, MD, PhD

David I. Bass, MD, PhD

Jennifer M. Bauer, MD, MS

Samuel R. Browd, MD, PhD

Seattle Children's Hospital, Seattle, WA

\section{References}

1. Archer J, Thatikunta M, Jea A. Posterior transdural approach for odontoidectomy in a child: case report. J Neurosurg Pediatr. 2020;25(1):8-12.

\section{Disclosures}

Dr. Bauer: consultant for DePuy Synthes.

\section{Correspondence}

Samuel R. Browd: samuel.browd@seattlechildrens.org.

INCLUDE WHEN CITING

Published online March 13, 2020; DOI: 10.3171/2020.1.PEDS2031.

\section{Response}

We thank Drs. Prolo, Bass, Bauer, and Browd for their interest in our article and for sharing their own experience with a posterior transdural odontoidectomy. Our colleagues seemed to have had difficulty accessing the odontoid through this approach because the position of the spinal cord precluded a safe corridor. When faced with this challenge, it may be useful to section the $\mathrm{C} 2$ nerve root and dentate ligaments. By sectioning these tethering structures, the spinal cord may be mobilized or gently rotated away from the odontoid without injury (and always utilizing intraoperative neuromonitoring), thereby creating a safe space to perform the odontoidectomy.

We look forward to reading about our colleagues' patient with longer-term follow-up.

Jacob Archer, MD

Riley Hospital for Children, Indiana University School of Medicine,

Indianapolis, IN

Meena Thatikunta, MD

University of Louisville Hospital School of Medicine, Louisville, KY

Andrew Jea, MD, MHA

Riley Hospital for Children, Indiana University School of Medicine, Indianapolis, IN

INCLUDE WHEN CITING

Published online March 13, 2020; DOI: 10.3171/2020.2.PEDS2071.

CAANS 2020, except where prohibited by US copyright law 